\title{
Endoscopic Retrograde Cholangiopancreatography in Nonagenarian Patients: Is It Really Safe?
}

\author{
Zain A Sobani ${ }^{1}$, Daria Yunina ${ }^{1}$, Anna Abbasi', Kevin Tin ${ }^{2}$, Daniel Simkin², Mary Rojas ${ }^{3,4}$, Yuriy Tsirlin², Ira Mayer ${ }^{2,5}$ \\ and Rabin Rahmani ${ }^{2,6}$ \\ ${ }^{1}$ Department of Medicine, ${ }^{2}$ Division of Gastroenterology, Department of Medicine, ${ }^{3}$ Department of Health Services Research, Maimonides \\ Medical Center, Brooklyn, NY, ${ }^{4}$ Department of Pediatrics, ${ }^{5}$ Department of Clinical Medicine, ${ }^{6}$ Division of Gastroenterology, Department of \\ Medicine, Albert Einstein College of Medicine, Yeshiva University, Bronx, NY, USA
}

Background/Aims: Literature on the safety of endoscopic retrograde cholangiopancreatography (ERCP) in elderly patients is divided. Based on this we decided to examine the safety of ERCP in nonagenarian patients.

Methods: A total of 1,389 patients, with a mean age of $63.94 \pm 19.62$ years, underwent ERCP during the study period. There were 74 patients aged 90 years or older with a mean age of $92.07 \pm 1.8$. Logistic regression showed that nonagenarian patients had a significantly increased odds of in-patient mortality (adjusted odds ratio $[\mathrm{AOR}]=9.6 ; 95 \%$ confidence interval $[\mathrm{CI}]=4,23 ; p \leq 0.001$ ). Charlson Comorbidity Index $(\mathrm{CCI}) \geq 2$ was also an independent predictor of in-patient mortality $(\mathrm{AOR}=2.4 ; 95 \% \mathrm{CI}=1.2,5.2$; $p=0.021)$. Age $\geq 90$ was not associated with increased adverse events; however emergency procedures $(\mathrm{AOR}=2.4 ; 95 \% \mathrm{CI}=1.5,4$; $p<0.001)$ and $\mathrm{CCI} \geq 2(\mathrm{AOR}=2.6 ; 95 \% \mathrm{CI}=1.7,4.0 ; p<0.001)$ were more likely to have adverse events.

Conclusions: Age $\geq 90$ and CCI $\geq 2$ are independently associated with increased odds of in-patient mortality in patients undergoing ERCP, whereas emergency procedures and CCI $\geq 2$ are associated with an increased adverse event rate. Caution must be exercised when considering ERCP in patients aged $\geq 90$ years and those with a CCI $\geq 2$. Clin Endosc 2018;51:375-380

Key Words: Cholangiopancreatography, endoscopic retrograde; Aged, 80 and over

\section{INTRODUCTION}

As the average life expectancy in the United States continues to rise, ${ }^{1}$ we expect to see an increase in the number of elderly patients with biliary pathology. ${ }^{2}$ Endoscopic retrograde cholangiopancreatography (ERCP) is an effective diagnostic and therapeutic procedure for patients with biliary obstruction. In the aging population, ERCP has been advocated as a therapeutic intervention in a variety of pancreato-biliary

Received: August 8, 2017 Revised: August 14, 2017

Accepted: August 18, 2017

Correspondence: Rabin Rahmani

Division of Gastroenterology, Department of Medicine, Maimonides Medical Center, 4802 10th Avenue, Brooklyn, NY 11219, USA

Tel: +1-718-283-6000, E-mail: Rrahmani@maimonidesmed.org

cc This is an Open Access article distributed under the terms of the Creative Commons Attribution Non-Commercial License (http://creativecommons.org/ licenses/by-nc/3.0) which permits unrestricted non-commercial use, distribution, and reproduction in any medium, provided the original work is properly cited. disorders in lieu of surgery. ${ }^{3}$ However, the procedure is not without risk. In the general population, ERCP is associated with a procedure-related mortality between $0.3 \%$ and $0.5 \%$ and an adverse event rate ranging from $5 \%$ to $10 \%$. ${ }^{2,4-6}$

Extrapolating from this data, ERCPs are being performed on increasingly older patients with little data regarding their safety in geriatric populations. Limited by small patient pools, data on the safety of ERCP in elderly patients is divided. Based on this we decided to evaluate the safety of ERCP in nonagenarian patients at our institution.

\section{MATERIALS AND METHODS}

After approval by the institutional review board, a retrospective chart review of patients undergoing ERCP at our institution was carried out. All patients undergoing primary diagnostic/therapeutic ERCP between January 1, 2012 and 
December 31, 2016 were abstracted. Patients undergoing follow-up ERCP for stent removal were excluded. The patients were divided into two groups based on their age (group 1 included patients aged 90 years and above; and group 2 included those aged between 18 and 89 years). The charts were reviewed for the presence of comorbidities, indications, procedure time, adverse events, and outcomes. Comorbidities were weighted using the Charlson Comorbidity Index (CCI). An arbitrary cutoff of $\mathrm{CCI} \geq 2$ was used to stratify the patients based on their comorbidities.

Indications were grouped into biliary stone disease (including choledocholithiasis and biliary pancreatitis), cholangitis, and abnormal imaging/tumors (including patients with known or suspected malignancy). Adverse events were grouped into major and minor. Major adverse events included bleeding requiring blood transfusions or interventions, mucosal injuries, perforations, cardio-pulmonary events, and procedure-related mortality. Minor adverse events included minor post-procedural bleeding evidenced by a drop in hemoglobin (not requiring transfusion or intervention), post-ERCP pancreatitis, or fevers. Self-limited post-sphincterotomy bleeding observed during the procedure, without a drop in post-procedure hemoglobin, was not considered as an adverse event. All major and minor adverse events were grouped together into a binary (yes/no) variable for analysis. While most studies on the topic considered procedure-related mortality as one of their outcome variables, we considered all-cause in-patient mortality during the index hospitalization as our outcome.

Descriptive analysis was performed by medians and interquartile ranges (IQRs) for continuous variables, as they were not normally distributed. Pearson's chi-squared, Fisher's exact, and Mann-Whitney $U$-tests were used to compare predictors by age group. Multivariate logistic regression was used to adjust for covariates.

\section{RESULTS}

A total of 1,389 patients, with a median age of 67 (IQR 52, 80) underwent primary ERCP at our center during the study period. The patients were predominantly female (59.4\%, $n=825)$ with a median CCI of 1.0 (IQR 0,2$)$. The most common indication was biliary stone disease accounting for $50.9 \%$ of the procedures, followed by tumors/abnormal imaging (32.1\%) and cholangitis (17.0\%). The overall procedural success rate was $89.4 \%$ with a median procedure time of 33 min (IQR 22:06, 50:27, $n=1,116$ ). Our overall adverse event rate was $7 \%$, with a major adverse event rate of $2 \%$ (Table 1 ). There were No procedure-related deaths; however all-cause in-patient mortality during the index hospitalization was $2.2 \%$. As described in the Methods an arbitrary cutoff of CCI $\geq 2$ was used to stratify the patients. Of the 1,389 patients, $28 \%(n=389)$ had a CCI $\geq 2$. Patients with a CCI $\geq 2$ had increased mortality $(4.1 \%[n=16]$ vs. $1.4 \%[n=14], p=0.002)$ and adverse events (10.8\% $[n=42]$ vs. $5.5 \%[n=55], p=0.001)$ compared to those with $\mathrm{CCI}<2$.

There were 74 patients $(5.3 \%)$ aged 90 years or older with a median age of 92 (IQR 90.75, 93) in group 1 compared to 1,315 patients $(94.7 \%)$ with a median age of 65 (IQR 50, 78) in group 2. Group 1 had more female patients compared to group 2 ( $73 \%$ vs. $58.6 \%, p=0.015)$. There was no difference in the procedural success rate between the groups $(89.2 \%$ vs. $89.4 \%, p=0.948)$. As expected, group 1 had a higher prevalence of periampullary diverticula $(28.4 \%$ vs. $10.6 \%$, $p=<0.001)$. The most common indication in both groups was biliary stone disease; however, group 1 had a higher proportion of patients with cholangitis ( $24.3 \%$ vs. $16.6 \%)$, whereas group 2 had a higher proportion of patients undergoing the procedure as a result of abnormal imaging or tumors (33.1\% vs. $14.9 \%$ ) (Table 1). There was a trend favoring increased sphincterotomies in group 1 ( $68.9 \%$ vs. $57.9 \%, p=0.062$ ); however, there was no difference in the percentage of patients undergoing stent placement in the two groups $(74.3 \%$ vs. $73.4 \%, p=0.867)$.

Both groups had an equal proportion of patients with a $\mathrm{CCI} \geq 2$ ( $29.7 \%$ vs. $27.9 \%, p=0.734)$. No significant difference was found in the composite adverse event rate between the two groups $(7.1 \%$ vs. $4.1 \%, p=0.310)$. Group 1 had a significantly higher all-cause in-patient mortality of $12.2 \%$ compared to $1.6 \%$ in group $2(p=<0.001)$.

\section{Multivariate analysis}

A multivariate model, taking into account emergency procedures, age, $\mathrm{CCI} \geq 2$, and indications, was created. For indications, biliary stone disease was considered as the reference constant. Logistic regression showed that age $\geq 90$ was not associated with increased adverse events, however emergency procedures (adjusted odds ratio $[\mathrm{AOR}]=2.45 ; 95 \%$ confidence interval $[\mathrm{CI}]=1.49,4.03 ; p<0.001)$ and $\mathrm{CCI} \geq 2(\mathrm{AOR}=2.58$; $95 \% \mathrm{CI}=1.66,4.00 ; p<0.001)$ were more likely to have adverse events when adjusted for the other variables. Interestingly, patients with cholangitis $(\mathrm{AOR}=0.49 ; 95 \% \mathrm{CI}=0.27,0.91 ; p=0.02$ ) and abnormal imaging/tumors (AOR $=0.35 ; 95 \% \mathrm{CI}=0.20,0.62$; $p<0.001$ ) had lower odds of adverse events (Table 2).

Patients in group 1 (nonagenarians) had significantly increased odds of in-patient mortality $(\mathrm{AOR}=9.5 ; 95 \% \mathrm{CI}=4$, 22.98 ; $p \leq 0.001$ ), adjusting for indications, CCI, and emergency procedures. $\mathrm{CCI} \geq 2$ was also an independent predictor of in-patient mortality $(\mathrm{AOR}=2.44 ; 95 \% \mathrm{CI}=1.15,5.2 ; p=0.021)$. 
Table 1. Summary of Patient Demographics with Distribution of Comorbidities, Indications, and Individual Adverse Events

\begin{tabular}{|c|c|c|c|c|}
\hline & $\begin{array}{c}\text { Overall } \\
(n=1,389)\end{array}$ & $\begin{array}{c}\text { Age } \geq 90 \\
(n=74)\end{array}$ & $\begin{array}{c}\text { Age }<90 \\
(n=1,315)\end{array}$ & $p$-value \\
\hline Age, median (IQR) & $67.0(52,80)$ & $92(91,93)$ & $65(50,78)$ & \\
\hline Charlson score, median (IQR) & $1.0(0.0,2.0)$ & $1.0(0.0,2.0)$ & $0.0(0.0,2.0)$ & $0.09^{\mathrm{a})}$ \\
\hline Charlson score $\geq 2, \%(n)$ & $28.0 \%(389)$ & $29.7 \%(22)$ & $27.9 \%(367)$ & $0.73^{\mathrm{b})}$ \\
\hline $\begin{array}{l}\text { Procedure time in minutes } \\
\text { median }(\mathrm{IQR})^{c)}\end{array}$ & $33: 00(22: 06,50: 27)$ & $33: 00(22: 00,50: 27)$ & $33: 00(24: 00,50: 48)$ & $0.76^{\mathrm{a})}$ \\
\hline Male, $\%(n)$ & $40.6 \%(564)$ & $27.0 \%(20)$ & $41.4 \%(544)$ & $0.02^{\mathrm{b})}$ \\
\hline Emergency, \% ( $n)$ & $15.4 \%(214)$ & $9.5 \%(7)$ & $15.7 \%(207)$ & $0.15^{\mathrm{b})}$ \\
\hline Success rate, $\%(n)$ & $89.4 \%(1242)$ & $89.2 \%(66)$ & $89.4 \%(1176)$ & $0.95^{\mathrm{b})}$ \\
\hline Periampullary diverticulum, $\%(n)$ & $11.5 \%(160)$ & $28.4 \%(21)$ & $10.6 \%(139)$ & $<0.001^{\text {b) }}$ \\
\hline Sphincterotomy, \% ( $n)$ & $58.5 \%(813)$ & $68.9 \%(51)$ & $57.9 \%(762)$ & $0.06^{\mathrm{b})}$ \\
\hline Rectal indomethacin, \% ( $n)$ & $27.3 \%(379)$ & $28.4 \%(21)$ & $27.2 \%(358)$ & $0.83^{\mathrm{b})}$ \\
\hline Stent placement, $\%(n)$ & $73.5 \%(1020)$ & $74.3 \%(55)$ & $73.4 \%(965)$ & $0.87^{\mathrm{b})}$ \\
\hline \multicolumn{5}{|l|}{ Ethnicity $^{\mathrm{e})}$} \\
\hline Caucasian (not Jewish or Hispanic) & $34.8 \%(484)$ & $36.5 \%(27)$ & $34.8 \%(457)$ & \\
\hline Jewish & $27.6 \%(383)$ & $51.4 \%(38)$ & $26.2 \%(345)$ & \\
\hline African American & $5.3 \%(73)$ & $1.4 \%(1)$ & $5.5 \%(72)$ & \\
\hline Asian & $19.8 \%(275)$ & $10.8 \%(8)$ & $20.3 \%(267)$ & \\
\hline South Asian & $1.4 \%(20)$ & - & $1.5 \%(20)$ & \\
\hline Hispanic & $3.3 \%(46)$ & - & $3.5 \%(46)$ & \\
\hline Native American & $0.8 \%(11)$ & - & $0.8 \%(11)$ & \\
\hline Middle Eastern & $4.1 \%(57)$ & - & $4.3 \%(57)$ & \\
\hline Other/no response & $2.8 \%(40)$ & - & $3.0 \%(40)$ & \\
\hline \multicolumn{5}{|l|}{ Comorbidities } \\
\hline Coronary artery disease & $6.7 \%(93)$ & $6.8 \%(5)$ & $6.7 \%(88)$ & $1^{\mathrm{d})}$ \\
\hline Congestive heart failure & $5.8 \%(81)$ & $18.9 \%(14)$ & $5.1 \%(67)$ & $<0.001^{\mathrm{d})}$ \\
\hline Chronic obstructive pulmonary disease & $3.7 \%(51)$ & $8.1 \%(6)$ & $3.4 \%(45)$ & $0.05^{\mathrm{d})}$ \\
\hline Chronic kidney disease & $3.0 \%(41)$ & $8.1 \%(6)$ & $2.7 \%(35)$ & $0.019^{\mathrm{d})}$ \\
\hline Cerebrovascular accident & $3.2 \%(45)$ & $8.1 \%(6)$ & $3.0 \%(39)$ & $0.029^{\mathrm{d})}$ \\
\hline Diabetes mellitus & $25 \%(347)$ & $20.3 \%(15)$ & $25.2 \%(332)$ & $0.336^{\mathrm{b})}$ \\
\hline Hypertension & $50.6 \%(703)$ & $73.0 \%(54)$ & $49.4 \%(649)$ & $<0.001^{\text {b) }}$ \\
\hline Peripheral vascular disease & $1.2 \%(17)$ & $4.1 \%(3)$ & $1.1 \%(14)$ & $0.058^{\mathrm{d})}$ \\
\hline Dementia & $2.7 \%(37)$ & $16.2 \%(12)$ & $1.9 \%(25)$ & $<0.001^{\mathrm{d})}$ \\
\hline Peptic ulcer disease & $4.2 \%(58)$ & $5.4 \%(4)$ & $4.1 \%(54)$ & $0.546^{\mathrm{d})}$ \\
\hline \multicolumn{5}{|l|}{ Indications } \\
\hline Biliary stones & $50.9 \%(707)$ & $60.8 \%(45)$ & $50.3 \%(662)$ & $0.004^{\mathrm{b})}$ \\
\hline Cholangitis & $17.0 \%(236)$ & $24.3 \%(18)$ & $16.6 \%(218)$ & $0.004^{\mathrm{b})}$ \\
\hline Abnormal imaging/mass & $32.1 \%(446)$ & $14.9 \%(11)$ & $33.1 \%(435)$ & $0.004^{\mathrm{b})}$ \\
\hline \multicolumn{5}{|l|}{ Outcomes } \\
\hline In-patient mortality, $\%(n)$ & $2.2 \%(30)$ & $12.2 \%(9)$ & $1.6 \%(21)$ & $<0.001^{\text {b) }}$ \\
\hline Overall adverse event rate & $7.0 \%(97)$ & $4.1 \%(3)$ & $7.1 \%(94)$ & $0.31^{\mathrm{b})}$ \\
\hline
\end{tabular}


Table 1. Continued

\begin{tabular}{llcl}
\hline & $\begin{array}{c}\text { Overall } \\
(\boldsymbol{n}=\mathbf{1 , 3 8 9})\end{array}$ & $\begin{array}{c}\text { Age } \geq \mathbf{9 0} \\
(\boldsymbol{n}=\mathbf{7 4})\end{array}$ & $\begin{array}{c}\text { Age }<\mathbf{9 0} \\
(\boldsymbol{n}=\mathbf{1 , 3 1 5})\end{array}$ \\
\hline Individual adverse events $^{\mathrm{e})}$ & & & $\boldsymbol{p}$-value \\
\hline Minor adverse event rate & $5.0 \%(69)$ & $4.1 \%(3)$ & $5.0 \%(66)$ \\
\hline Major adverse event rate & $2.0 \%(28)$ & - & $2.1 \%(28)$ \\
\hline Minor bleeding & $1.2 \%(16)$ & $1.4 \%(1)$ & $1.1 \%(15)$ \\
\hline Fever & $1.7 \%(23)$ & $1.4 \%(1)$ & $1.7 \%(22)$ \\
\hline Post-ERCP pancreatitis & $2.2 \%(30)$ & $1.4 \%(1)$ & $2.2 \%(29)$ \\
\hline Mucosal injuries & $0.1 \%(1)$ & - & $0.1 \%(1)$ \\
\hline Bleeding requiring transfusion & $1.2 \%(16)$ & - & $1.2 \%(16)$ \\
\hline Bleeding requiring intervention & $0.6 \%(8)$ & - & $0.6 \%(8)$ \\
\hline Perforation & $0.2 \%(3)$ & - & $0.2 \%(3)$ \\
\hline
\end{tabular}

IQR, interquartile range; ERCP, endoscopic retrograde cholangiopancreatography.

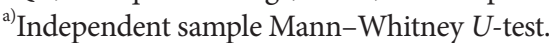

${ }^{\text {b) }}$ Pearson chi-squared test.

${ }^{c} n=1,116$.

${ }^{\mathrm{d})}$ Fisher's exact test.

${ }^{\text {e) }}$ Cell sizes are too small for analyses.

Table 2. Summary of Multivariate Analysis Taking into Account Emergency Procedures, $\mathrm{Age}, \mathrm{CCl} \geq 2$, and Indications

\begin{tabular}{|c|c|c|c|c|}
\hline & & $95 \% \mathrm{c}$ & erval & \\
\hline & Adjusted odis ratio & Lower & Upper & $p$-value \\
\hline Adverse events & & & & \\
\hline Emergency procedure & 2.45 & 1.49 & 4.03 & $<0.001$ \\
\hline $\mathrm{CCI} \geq 2$ & 2.58 & 1.66 & 4.00 & $<0.001$ \\
\hline Age $\geq 90$ & 0.52 & 0.16 & 1.70 & 0.28 \\
\hline Cholangitis $^{\mathrm{a})}$ & 0.49 & 0.27 & 0.91 & 0.02 \\
\hline Abnormal imaging/mass ${ }^{\mathrm{a})}$ & 0.35 & 0.20 & 0.62 & 0.35 \\
\hline Mortality & & & & \\
\hline Emergency procedure & 0.72 & 0.23 & 2.23 & 0.57 \\
\hline $\mathrm{CCI} \geq 2$ & 2.44 & 1.15 & 5.20 & 0.02 \\
\hline Age $\geq 90$ & 9.58 & 4.00 & 22.98 & $<0.001$ \\
\hline Cholangitis $^{\text {a) }}$ & 3.98 & 1.42 & 11.20 & 0.01 \\
\hline Abnormal imaging/mass ${ }^{\text {a) }}$ & 3.26 & 1.23 & 8.62 & 0.02 \\
\hline
\end{tabular}

CCI, Charlson Comorbidity Index.

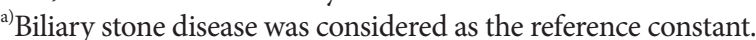

Patients with cholangitis $(\mathrm{AOR}=3.98$; $95 \% \mathrm{CI}=1.42,11.2$; $p=0.01$ ) and abnormal imaging/tumors (AOR $=3.26$; $95 \%$ $\mathrm{CI}=1.23,8.62 ; p=0.02)$ had increased odds of in-patient mortality compared to patients with biliary stones when adjusting for age, $\mathrm{CCI}$, and emergency procedures.

\section{DISCUSSION}

As average life expectancy continues to increase world- wide, medical professionals are faced with an increasingly older population requiring invasive procedures. The care of geriatric patients is complicated by overall frailty, in addition to a host of comorbidities and polypharmacy as a result of these comorbid conditions. As discussed earlier, invasive procedures are frequently carried out on geriatric patients with limited population-specific safety data. Although multiple studies on the safety of ERCPs in octogenarians and nonagenarians have been published, the data available does not provide conclusive evidence due to small sample sizes and a 
Table 3. Summary of Results from Studies Evaluating the Adverse Events of ERCP in Nonagenarian Patients

\begin{tabular}{|c|c|c|c|c|c|c|c|c|c|c|}
\hline \multirow[t]{2}{*}{ Author } & \multirow[t]{2}{*}{ Year } & \multirow[t]{2}{*}{ Region } & \multicolumn{2}{|c|}{$\begin{array}{c}\text { No. of procedures/ } \\
\text { patients }\end{array}$} & \multicolumn{2}{|c|}{ Success rate } & \multicolumn{2}{|c|}{$\begin{array}{l}\text { Adverse event } \\
\text { rate }\end{array}$} & \multicolumn{2}{|c|}{ Mortality rate } \\
\hline & & & $\geq 90$ & $<90$ & $\geq 90$ & $<90$ & $\geq 90$ & $<90$ & $\geq 90$ & $<90$ \\
\hline Sugiyama et al. ${ }^{16}$ & 2000 & Japan & 22 & 381 & $100.0 \%$ & $98.4 \%$ & $4.5 \%$ & $6.8 \%$ & $0 \%$ & $0.3 \%$ \\
\hline Rodríguez-González et al. ${ }^{15}$ & 2003 & Spain & 126 & - & $90.5 \%$ & - & $2.5 \%$ & - & $0.7 \%$ & - \\
\hline Mitchell et al. ${ }^{14}$ & 2003 & Ireland & 23 & - & $91.3 \%$ & - & $13.0 \%$ & - & $13 \%^{a)}$ & - \\
\hline Hui et al. ${ }^{12, c)}$ & 2004 & Hong Kong & 64 & 165 & $98.4 \%$ & $92.7 \%$ & $4.7 \%$ & $7.3 \%$ & $7.8 \%^{\mathrm{b})}$ & $4.2 \%^{\mathrm{b})}$ \\
\hline Huguet et al. ${ }^{11}$ & 2005 & Spain & 42 & - & $85.7 \%$ & - & $14.4 \%$ & - & $0 \%$ & - \\
\hline Katsinelos et al. ${ }^{13}$ & 2006 & Greece & 63 & 350 & $98.4 \%$ & $99.1 \%$ & $6.3 \%$ & $8.4 \%$ & $1.6 \%$ & $0.6 \%$ \\
\hline Cariani et al. ${ }^{8}$ & 2006 & Italy & 40 & - & $82.0 \%$ & - & $0.0 \%$ & - & $0 \%$ & - \\
\hline Grönroos et al. $^{9}$ & 2010 & Finland & 41 & - & - & - & $7.0 \%$ & - & $10 \%^{\mathrm{d})}$ & \\
\hline Hu et al. ${ }^{10}$ & 2014 & China & 78 & 312 & $91.0 \%$ & $96.2 \%$ & $7.7 \%$ & $7.4 \%$ & - & - \\
\hline Yun et al. ${ }^{17}$ & 2014 & Korea & 43 & 129 & $86.0 \%$ & $94.0 \%$ & $12.0 \%$ & $22.0 \%$ & $2 \%$ & $0 \%$ \\
\hline This study & & US & 74 & 1,315 & $89.2 \%$ & $89.4 \%$ & $4.1 \%$ & $7.1 \%$ & $12.2 \%^{\mathrm{a})}$ & $1.6 \%{ }^{\mathrm{a})}$ \\
\hline
\end{tabular}

ERCP, endoscopic retrograde cholangiopancreatography.

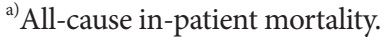

${ }^{b)}$ Thirty-day mortality.

${ }^{c}$ All patients underwent the procedure for cholangitis.

${ }^{\mathrm{d})}$ Early mortality, unclear definition.

lack of control groups (Table 3). ${ }^{7-17}$

Our study evaluated 1,389 patients undergoing ERCP at a single center over a period of 5 years. During this period, 74 patients (5.3\%) were aged 90 years or older at the time of the procedure. We excluded patients undergoing ERCP for stent removal from our sample considering the different nature of the procedure. Although comorbidities were differently distributed between the two groups (Table 1), they were comparable when weighted using the CCI. An arbitrary cutoff of $\mathrm{CCI} \geq 2$ was used to stratify the patients. Both groups had an equal proportion of patients with a CCI $\geq 2$ (29.7\% vs. $27.9 \%$, $p=0.734$ ).

Biliary stones were the predominant indication for the procedure in both groups. Group 2 had an increased proportion of patients undergoing ERCP due to abnormal radiological findings and tumors compared to the older population, which had a higher proportion of patients with cholangitis. Although speculative, this finding may represent a tendency toward less aggressive care in elderly patients rather than a decreased incidence of tumors and abnormal radiological findings. There was no difference in the procedural success rates between the 2 groups.

We did not find any increase in the odds of adverse events in the patients aged $\geq 90$ years when compared to younger patients on univariate and multivariate analyses. However, an increased odds of adverse events was noted with emergency procedures $(\mathrm{AOR}=2.45)$ and a $\mathrm{CCI} \geq 2(\mathrm{AOR}=2.58)$. These findings were comparable to other studies reported in literature. Table 2 highlights the findings of identified studies evaluating the safety of ERCP in nonagenarian patients. Of the identified studies 5 had control groups. .0,12,13,16,17 $^{\text {These }}$ studies also failed to show any significant difference in the procedural success or composite adverse event rates in nonagenarian patients. Studies have shown a reduced incidence of post-ERCP pancreatitis in the elderly. ${ }^{17,18}$ Although we did see a trend toward reduced post-ERCP pancreatitis in nonagenarian patients, we were unable to analyze individual adverse events owing to the low rate of adverse events and small sample size (Table 1).

Finkelmeier et al. noted that although the rate of procedure-related mortality was comparable between older (aged 80 years or older) and younger patients, the rate of sedation-related adverse events was higher in the older population. ${ }^{18}$ Furthermore, Fisher et al. prospectively examined 130 sequential ERCP patients for post-procedure cardiopulmonary adverse events and found patients over the age of 65 to have an increased rate of new onset electrocardiogram changes and myocardial injury (as evidenced by a rise in cardiac troponins at $24 \mathrm{~h}$ post-procedure). ${ }^{19}$

Most studies have reported no significant differences in procedure-related mortality rates between younger and older populations. We did not have any procedure-related deaths in our sample. From a patient stand-point, we considered all-cause in-patient mortality during the index admission as our primary outcome and found a significantly increased all-cause in-patient mortality in patients aged 90 years and 
above (12.2\% vs. $1.6 \%$, AOR 9.6). Mitchell et al., with a sample of 23 patients aged 90 years and above, reported a comparable all-cause in-patient mortality rate of $13 \%$, and Grönroos et al. reported an "early mortality" rate of $10 \% .{ }^{9,14}$ Both studies did not have a control group, and Grönroos et al. did not clearly define what they meant by early mortality. ${ }^{9,14}$

Hui et al. reported a 30-day mortality in patients undergoing emergency ERCPs for cholangitis and did not find any significant difference between nonagenarians and the younger population $(7.8 \%$ vs. $4.2 \%, p=0.227) .^{12}$ A meta-analysis conducted in 2014 found increased rates of bleeding (incidence rate ratio [IRR] 2.4), cardiopulmonary events (IRR 3.7), and death (IRR 3.8) in nonagenarian patientscompared to patients aged $<65$ years. ${ }^{2}$

Although one can argue that the all-cause in-patient mortality was not directly attributable to the procedure itself but rather to the patients' pathology, we recommend that ERCPs be approached with caution in nonagenarian patients and those with a $\mathrm{CCI} \geq 2$.

\section{LIMITATIONS}

The analyses were limited by the small sample size, particularly as it obtained from one site. Considering the sample size and rarity of certain adverse events and outcomes, and demographic variability, we were unable to tease out many covariates. That being said, our sample size of patients aged 90 and above was among the largest studies of its type.

\section{Conflicts of Interest}

The authors have no financial conflicts of interest.

\section{REFERENCES}

1. Xu J, Murphy SL, Kochanek KD, Arias E. Mortality in the United States, 2015. NCHS Data Brief 2016:1-8.
2. Day LW, Lin L, Somsouk M. Adverse events in older patients undergoing ERCP: a systematic review and meta-analysis. Endosc Int Open 2014;2:E28-E36.

3. Siegel JH, Kasmin FE. Biliary tract diseases in the elderly: management and outcomes. Gut 1997;41:433-435.

4. Andriulli A, Loperfido S, Napolitano G, et al. Incidence rates of post-ERCP complications: a systematic survey of prospective studies. Am J Gastroenterol 2007;102:1781-1788.

5. ASGE Standards of Practice Committee, Anderson MA, Fisher L, et al. Complications of ERCP. Gastrointest Endosc 2012;75:467-473.

6. Freeman ML, Nelson DB, Sherman S, et al. Complications of endoscopic biliary sphincterotomy. N Engl J Med 1996;335:909-918.

7. Baillie J. ERCP in the elderly: handle with care. Endosc Int Open 2014;2:E43-E44.

8. Cariani G, Di Marco M, Roda E, Solmi L. Efficacy and safety of ERCP in patients 90 years of age and older. Gastrointest Endosc 2006;64:471472.

9. Grönroos JM, Salminen P, Laine S, Gullichsen R. Feasibility of ERCP procedures in patients 90 years of age and older. J Clin Gastroenterol 2010;44:227-228.

10. Hu L, Sun X, Hao J, et al. Long-term follow-up of therapeutic ERCP in 78 patients aged 90 years or older. Sci Rep 2014;4:4918.

11. Huguet JM, Sempere J, Bort I, et al. [Complications of endoscopic retrograde cholangiopancreatography in patients aged more than 90 years old]. Gastroenterol Hepatol 2005;28:263-266.

12. Hui CK, Liu CL, Lai KC, et al. Outcome of emergency ERCP for acute cholangitis in patients 90 years of age and older. Aliment Pharmacol Ther 2004;19:1153-1158

13. Katsinelos P, Paroutoglou G, Kountouras J, Zavos C, Beltsis A, Tzovaras G. Efficacy and safety of therapeutic ERCP in patients 90 years of age and older. Gastrointest Endosc 2006;63:417-423.

14. Mitchell RM, O'Connor F, Dickey W. Endoscopic retrograde cholangiopancreatography is safe and effective in patients 90 years of age and older. J Clin Gastroenterol 2003;36:72-74.

15. Rodríguez-González FJ, Naranjo-Rodríguez A, Mata-Tapia I, et al. ERCP in patients 90 years of age and older. Gastrointest Endosc 2003;58:220-225.

16. Sugiyama M, Atomi Y. Endoscopic sphincterotomy for bile duct stones in patients 90 years of age and older. Gastrointest Endosc 2000;52:187191.

17. Yun DY, Han J, Oh JS, Park KW, Shin IH, Kim HG. Is endoscopic retrograde cholangiopancreatography safe in patients 90 years of age and older? Gut Liver 2014;8:552-556.

18. Finkelmeier F, Tal A, Ajouaou M, et al. ERCP in elderly patients: increased risk of sedation adverse events but low frequency of post-ERCP pancreatitis. Gastrointest Endosc 2015;82:1051-1059.

19. Fisher L, Fisher A, Thomson A. Cardiopulmonary complications of ERCP in older patients. Gastrointest Endosc 2006;63:948-955. 